\title{
Risk Perception and Condom-use among Thai Youths: Findings from Kanchanaburi Demographic Surveillance System Site in Thailand
}

\author{
Mohammad Raisul Haque' and Amara Soonthorndhada ${ }^{2}$ \\ 'BRAC Health Programme, BRAC, BRAC Centre, Mohakhali, Dhaka 1212, Bangladesh and ${ }^{2}$ Institute for Population and Social \\ Research, Mahidol University, Salaya, Phuttamonthon, Nakhonpathom, Thailand
}

\begin{abstract}
Youths, aged 15-24 years, comprise a large fragment of the total population in Thailand, and unsafe sexual behaviours are increasing, nowadays, among young people. The study was conducted to explore the characteristics of youths and other conducive, facilitating and reinforcing factors associated with risk perception of sexually transmitted infections (STIs) among the study population. Data employed in this study were derived from the site of the Kanchanaburi Demographic Surveillance System of Thailand 2004 using a stratified systemic design. The study population was mainly young current condom-users aged 15-24 years, and cross-sectional analysis was done on this populace. The findings revealed that youths who fell into the single (unmarried) category having temporary partners were more likely to perceive the risks associated with STIs in relation to using condom. A greater proportion of unmarried youths was engaged in sexual activity before the age of 20 years and that condom-use was also inconsistent. Youths having temporary partners were more likely to perceive risk and reason for using a condom than when with their regular partner. Education played a significant role in risk perception of STIs. Risk perception was increasing with the increasing level of education. Other conducive and facilitating factors, such as household wealth, living in urban or semi-urban areas, and access to mass media such as television, also had a positive influence on risk perception. The odds ratio showed that condom-users who had indulgence in liquor were less likely to perceive the risk of STIs. Overall, socioeconomic status had a great influence on risk perception of STIs. Finally, youths exhibiting high-risk sexual behaviour need realistic risk assessments and positive ways of incorporating condom into their sexual lives.
\end{abstract}

Key words: Condom-use; Education; Risk perception; Sexual partners; Youths; Thailand

\section{INTRODUCTION}

The worldwide increase in the prevalence of human immunodeficiency virus (HIV) and other sexually transmitted infections (STIs) has created a multifaceted public-health problem, affecting individual lives and the ability of families and communities to cope with the devastating social, cultural, economic and health consequences (1).

The rate of HIV infection among young people is

Correspondence and reprint requests should be addressed to:

Mr. Mohammad Raisul Haque

Senior Sector Specialist

BRAC Health Programme

BRAC

BRAC Centre

Mohakhlai, Dhaka 1212

Bangladesh

Email: raisul.h@brac.net growing rapidly; $67 \%$ of newly-infected individuals in developing countries are young people aged 1524 years, and 5,000-6,000 young people become infected every day (2). Thailand has turned the tide of its epidemic, and the impact of its effective prevention efforts is vividly apparent. The comprehensive national response of Thailand to the HIV/AIDS epidemic has been extensively documented since its beginning. Substantial progress in the fight against HIV/AIDS has been made because awareness of the problem was raised. Behavioural change resulting in increased condom-use in brothels on a national scale rose from virtually nil to more than $95 \%$. Despite these achievements and different efforts, according to the United Nations Joint Programme on HIV/AIDS (3), the prevalence of HIV among Thai people aged 22 years or younger rose from $13 \%$ in 2003 to $22 \%$ in 2005 . Youths are also putting themselves at a high risk of contracting sexually trans- 
mitted diseases (STDs) or, worse, HIV/AIDS, due to their indulgence in premature sex $(4,5)$, male homosexuality (6-8), and intravenous drug-uses (9).

Various studies have shown that youths are far from systematically using condoms in their sexual relationships (10-12). A study in Thailand revealed that men aged 21-25 years did not comprehend the risks of contracting HIV/AIDS and, hence, displayed high-risk behaviour (13). The low rate of condom-use might have been due to 'lack of perceived susceptibility' to the negative outcomes of unprotected premarital sexual behaviour. Young people are inconsistent condom-users, and it is established that the risk of HIV is greater among those who are inconsistent users than among non-users (14). Im-em conducted a study in the mid-1990s in Chiang Mai villages, which discovered that a large number of Thai men abstained from sexual contact with prostitutes in those years due to fear of contracting HIV; however, there was a tendency for an increasing number of them having sexual contact with non-paid partners without condom-use (15). This further emphasizes the need to understand the pathways of condom-use and risk perception among youths with different characteristics to protect themselves from STIs. The dynamics of sexual relations and its effect on the youth's abilities to determine risks associated with sexual behaviour has not been thoroughly investigated (16) but it is known that, generally, they grossly underestimate the risk of becoming infected with HIV/AIDS.

Risk perception is the subjective judgement that people make about the characteristics and severity of a risk. Risk has been defined in a number of ways but it is often seen as the likelihood that an individual will experience the effect of danger (17). Smith has suggested that, among many people, risk assessment is based on perceptions of a general rather than personal vulnerability to infection, and it is usually conceptualized in terms of those with multiple sexual partners (18). Wherever it is discussed, there seems to be a consensus about the essence of risk consisting of the probability of an adverse event and the magnitude of its consequences (19). However, risk perception is the subjective assessment of the probability of a specified type of incident occurring and how concerned we are with the consequences. Perception of risk includes evaluations of the probability and the consequences of a negative outcome for a person. Risk appears to mean different things to different people, and actions and understanding about risks are learnt by socially- and culturally-structured conceptions.
Therefore, perception of risk goes beyond the individual, and it is a social and cultural construct reflecting values, symbols, history, and ideology (20). Risk perceptions have, to a great extent, been studied exclusively with individuals collecting, processing, and forming perceptions as atomized units unconnected to a social system (21).

The relationship between individuals' perceptions of their risk for acquiring STIs/HIV and their use of condoms is poorly understood. Understanding this relationship is crucial to the development of effective strategies to fight HIV and AIDS (22). Perception of risk is considered to be the first stage towards behavioural change from risk-taking to safer behaviour (23). The individual subjective state of willingness to prevention and control measures is determined by an individual's perceptions, likelihood of susceptibility to STIs, and the probable severity of the consequences of contracting HIV/ AIDS. The concept of perceived risk refers to a general assessment of one's risk to the health hazard and is distinct from beliefs about the consequences of condom-use. The belief that using a condom could prevent infections due to STIs/HIV will encourage condom-use.

Therefore, an examination of perceptions of youths about STIs/HIV risk is important in understanding how youths relate their sexual experiences to the risk of disease or infection. Perceived risk of getting STIs/HIV may have important implications for health if the perceptions are rational and lead to a willingness to avoid risky behaviour. An understanding of the association between perception of risk and sexual behaviour may also facilitate the design of AIDS-prevention measures necessary to check its spread among different population subgroups (24).

A wide range of the socioeconomic, demographic and cultural factors operates jointly and exerts varying degrees of influence upon the different life-events underlying the sociosexual maturation process among young adults in Thailand. In earlier days, the experience of having first sexual intercourse with a prostitute was strongly influenced by friends and facilitated by social drinking (25). Furthermore, prostitute patronage was seen as a form of entertainment providing men with pleasure; thus, it has been substantially promoted as an activity of single and married men who usually visit prostitutes in a group of friends. The term khun khru meaning 'up teacher' or to have the first sex with an experienced woman, usually a commercial 
sex worker, was well-recognized (26). In a study in Thailand, O'Connor found that married males were less likely to use condom (27). Results of another study in Thailand by Knodel and Pramuralratana among general population showed that no more than $2 \%$ of married couples used condoms (28). Michel reported that educated men in developing countries are more likely to engage in non-regular sex but they are also more likely to use condoms within those relationships (29). In a study in developed countries, Oddens and Lehert also found that condom-use increases with an increasing education level (30). Youths having high household wealth are more likely to perceive self-risk and practise condom-use. In a study in Samutprakan province, Thailand, Guaykietikul et al. found that age, marital status, level of education, and monthly income were associated with condom-use but occupation was not (31). Results of the Kanchanaburi Demographic Surveillance System (KDSS) survey (2003) on method of contraceptive-choice showed that condom was more preferable to couples in urban and semi-urban areas than in other strata (32). Results of the National Sexual Behaviour Survey of Thailand (2006) showed that mass media, especially television, was the most popular source of information on AIDS prevention (33). Another study in northern Thailand found that consumption of alcohol was associated with several measures of sexual activity among respondents (34). If men are not drunk, they may be better able to evaluate risk; they may restrain from unsafe sexual practices. The study by Alice and others in Thailand also revealed that, at any given age, sexual initiation was associated with having a non-agricultural background and using alcohol or other such substances (35).

The objectives of the study were, therefore, to explore how irrational perception and behaviour threaten the health risks of the people in a community who are particularly susceptible to be infected with STIs/HIV infections. To be able to understand the risk perception of the youth and the use of condom, it is imperative to ponder the other conducive factors that may be influencing risk perception and condom-use. To detect the association between sociodemographic variables of condomusers and perception of risk, the study has been designed to specifically collect data from youths to investigate the inter-linkage among the behaviour, environment, socioeconomic and cultural factors that influence perception of risk and condom-use.

\section{Conceptual framework}

Condom-use is generally influenced by the complex interaction of a number of factors. Rogers and
Hackenberg defined the distinctive behaviours of people not in terms of avoiding risks but in terms of taking risks for morbidity and mortality (36). Therefore, the Health Belief Model (HBM) is a framework that uses the desire to avoid a negative health consequence for motivating people to take positive health actions. The HBM has been used since 1950 for exploring various health behaviours in different populations (37). People are ready to act if they believe that they are susceptible to the condition (perceived susceptibility), believe that the condition has serious consequences (perceived severity), that taking action would reduce their susceptibility to the condition or its severity (perceived benefits), and that costs of taking action (perceived barriers) are outweighed by the benefits. Self-efficacy includes the person's perception on how likely they are to change particular behaviours and exposed to factors that prompt action is taken (cue to action) where people are confident in their ability to successfully perform an action.

The analysis below draws upon the HBM. In particular, it regards the use of condom as a result of three sets of independent factors: sociodemographic, social structure, and access to mass media and substance-use. Sociodemographic factors are the tendency of individuals to use condom, which include demographic characteristics (age, sex, and marital status) and social structure (education, occupation, household wealth, and place of residence). Access to the mass media factor refers to the ability of an individual to afford and get access to information through radio or television, which can impinge upon condom-use. Type of sexual partners and substance-use, e.g. social drinking, such as beer or liquor, mainly come from friends' influence. Paying for sex with prostitutes is another common behaviour among Thai men. 'Risk perception' is the dependent variable, and it is a measure of whether respondents used condoms for their own health benefit, i.e. to avoid being infected with STIs/HIV from their partners during intercourse.

\section{MATERIALS AND METHODS}

\section{Study area}

The study area is the site of the Kanchanaburi Demographic Surveillance System (KDSS), a project of the Institute for Population and Social Research (IPSR), Mahidol University, Thailand, with support from the Welcome Trust Foundation of the United Kingdom (38). This project area is located in Kanchanaburi province, which is the third largest prov- 
ince of Thailand situated in the western part of the central region. The main objective of the KDSS is to document population changes in the study areas in relation to social, economic and environmental changes in the community.

\section{Source of data}

The KDSS used a stratified systematic sampling design to select 100 communities (villages and census blocks) from a sampling frame constructed for the 2000 census. These sites were selected by applying stratified systemic cluster-sampling technique to 1,004 villages/census blocks of five strata in Kanchanaburi province. So, the primary sampling units for rural and urban areas were villages and census blocks respectively. According to the main occupation of the population and land-use patterns, the whole province and the study area were divided into five strata, such as urban/semi-urban, rice-field, plantation, upland, and mixed economy (39). Data collected in 2004 (Round 5) under the KDSS were used for this study.

\section{Method of data collection}

The method used for data collection was structured interview and entailed the use of three sets of questionnaire: village, household, and individual. The method of face-to-face interviews used in each previous census-rounds was used in this round as well. A community census approach was employed in collecting data from both households and individuals aged 15 years and over. At the household level, basic information about household members and household characteristics was obtained by interviewing household heads. Data collection started on 1 July 2004 and ended on 28 August 2004 (59 days in total) in Round 5 (2004). Ten teams were responsible for collecting data. Each team consisted of one field supervisor and 6-10 interviewers, depending upon the number of villages and area to be covered. In evaluating the quality of data, opinions of the interviewers were recorded at the end of each household and individual interview. At the individual level, information was collected by interviewing all available individuals, aged 15-24 years, on their health and health risk behaviours, along with other socioeconomic and demographic characteristics.

\section{Study population}

This study mainly focused on male condom-users (consistent and inconsistent) aged 15-24 years. In Round 5 (2004), 2,194 male individuals aged 15-24 years were questioned about their current condom- use and type of their sexual partners during the past one year, i.e. from 1 July 2003 to 30 June 2004 (12 months), and 195 respondents were found for the sample size.

\section{Methods of analysis}

Univariate analysis was conducted to examine the background characteristics of youths. In trying to understand the relationship between risk perception in using condoms and other sociodemographic factors, household wealth, geographical variances, type of partners, access to mass media, and substance-use were employed in both bivariate and multivariate analyses. Logistic regression was used for examining the relationship between risk perception of infection among condom-users and different characteristics and other factors that are likely to influence individual's risk perception. In regression, the new predictor was added in the model because this new predictor could increase the explanatory power for the new model. Otherwise, the predictor was dropped out from the model. This was done by starting with a model that includes age, marital status, education, and occupation as the independent variables, i.e. Model 1. Subsequently, blocks of variables were added in a stepwise approach (Model 2= Model 1 + household wealth; Model 3= Model $2+$ place of residence; Model $4=$ Model $3+$ access to mass media (having or not having TV and radio); Model 5= Model $4+$ type of sexual partners, substance-use, like drinking beer and liquor), and their effects were ascertained.

\section{RESULTS}

\section{Sample characteristics}

In total, 195 respondents, aged 15-24 years, used condoms during 1 July 2003-30 June 2004, during the survey in the KDSS site.

Table 1 presents profiles of the respondents included in the study sample. In general, about half of the respondents were aged 15-19 years, and just slightly more than half were aged 20-24 years. More than three-fourths of the respondents were unmarried, and about two in 10 were married. One-fourth of the respondents completed primary education, more than a quarter completed lower secondary, and three in 10 upper secondary, and one in 10 had attained more than upper secondary level.

Among youths, one-fourth of the respondents in the occupation category, were students, a quarter were labourers and transport workers, more than a quarter were involved in agricultural work, and a small proportion was in sales, services, and pro- 
Table 1. Percentage distribution of youths $(n=195)$ according to selected characteristics of current condom-users, Kanchanaburi Demographic Surveillance System site, 2004

\begin{tabular}{|c|c|}
\hline Characteristics & $\%$ \\
\hline \multicolumn{2}{|l|}{ Age (years) } \\
\hline $15-19$ & 48.2 \\
\hline $20-24$ & 51.8 \\
\hline \multicolumn{2}{|l|}{ Marital status } \\
\hline Single & 83.1 \\
\hline Married & 16.9 \\
\hline \multicolumn{2}{|l|}{ Education } \\
\hline No schooling & 5.1 \\
\hline Primary school & 25.1 \\
\hline Lower secondary school & 28.7 \\
\hline Upper secondary school & 30.3 \\
\hline More than upper secondary level & 10.8 \\
\hline \multicolumn{2}{|l|}{ Occupation } \\
\hline Not working & 5.6 \\
\hline Study & 25.6 \\
\hline Agriculture & 28.7 \\
\hline Labour and transport-related work & 26.2 \\
\hline Professional, sales, and services & 13.8 \\
\hline \multicolumn{2}{|l|}{ Household wealth* $^{*}$} \\
\hline Below average & 15.4 \\
\hline Average & 48.2 \\
\hline High & 36.4 \\
\hline \multicolumn{2}{|l|}{ Place of residence } \\
\hline Urban/semi-urban & 33.3 \\
\hline Rice-field & 20.0 \\
\hline Plantation & 15.9 \\
\hline Uplands & 16.4 \\
\hline Mixed economy & 14.4 \\
\hline \multicolumn{2}{|l|}{ Access to mass media } \\
\hline TV & 92.3 \\
\hline Radio & 50.3 \\
\hline \multicolumn{2}{|l|}{ Substance-use } \\
\hline Beer & 81.5 \\
\hline Liquor & 76.4 \\
\hline \multicolumn{2}{|l|}{ Use of condom to prevent STIs } \\
\hline Prevent STIs (risk perception) & 37.9 \\
\hline Use for other reasons & 62.1 \\
\hline Total & 100 \\
\hline
\end{tabular}

${ }^{*}$ Household wealth index used for describing household economic status was constructed using principal component analysis from the selected items. Initially, this index was ranked into five different wealth quintiles, ranging from the lowest quintile to the highest quintile. There was an equal distribution of each quintile, with each quintile containing $20 \%$ of the responde-dents. These five groups were then re-grouped into three categories, which were designated as below average, average, and high; STIs=Sexually transmitted infections fessional groups. Nearly half of the respondents were from households with average wealth, more than one-third were from wealthy households, and a small percentage belonged to households with below average wealth. The majority (66.7\%) of the respondents were rural residents, and onethird were from urban and semi-urban areas. Most (92.3\%) had access to television, and half of them had access to radio. More than three-fourths of the respondents were indulged in substances, such as beer and liquor, during the last 12 months. In general, of all the condom-users, $37.9 \%$ perceived self-risk to protect themselves from STIs, and $62.1 \%$ were using condoms for other reasons, e.g. prevent pregnancy, prevent messy and menstruation of the partner.

Table 2 presents the condom-use practice and source of condoms during the last 12 months. Of the youths, slightly more than half were regular

Table 2. Percentage distribution of current use of condoms and sources of condom for youths $(n=195)$ in the Kanchanaburi Demographic Surveillance System site, 2004

\begin{tabular}{|lc|}
\hline Characteristics & $\%$ \\
\hline Current user (in the last 12 moths) & \\
Consistent user & 51.3 \\
Inconsistent user & 48.7 \\
Source of condom & \\
Drug-store & 64.6 \\
Public hospital, health centre, and & 21.5 \\
private hospital & 13.9 \\
Friend and other sources & 100 \\
Total & \\
\hline
\end{tabular}

condom-users, and just less than half did not either use condoms regularly or used it occasionally. The most common source of condoms was drug-stores, and more than one-fifth of the respondents had access to condoms from public hospitals, health centres, and private hospitals. A small percentage of the respondents received condoms from friends and other sources.

\section{Initiation of condom-use and pattern of use}

Table 3 shows the patterns of condom-use, including age of the respondents when they used a condom for the first time, type of partner with whom they used a condom for the first time, and the reason they first used a condom. The first use of condom among the youths aged less than 15 years was around $6 \%$. A large proportion (78.5\%) of the 


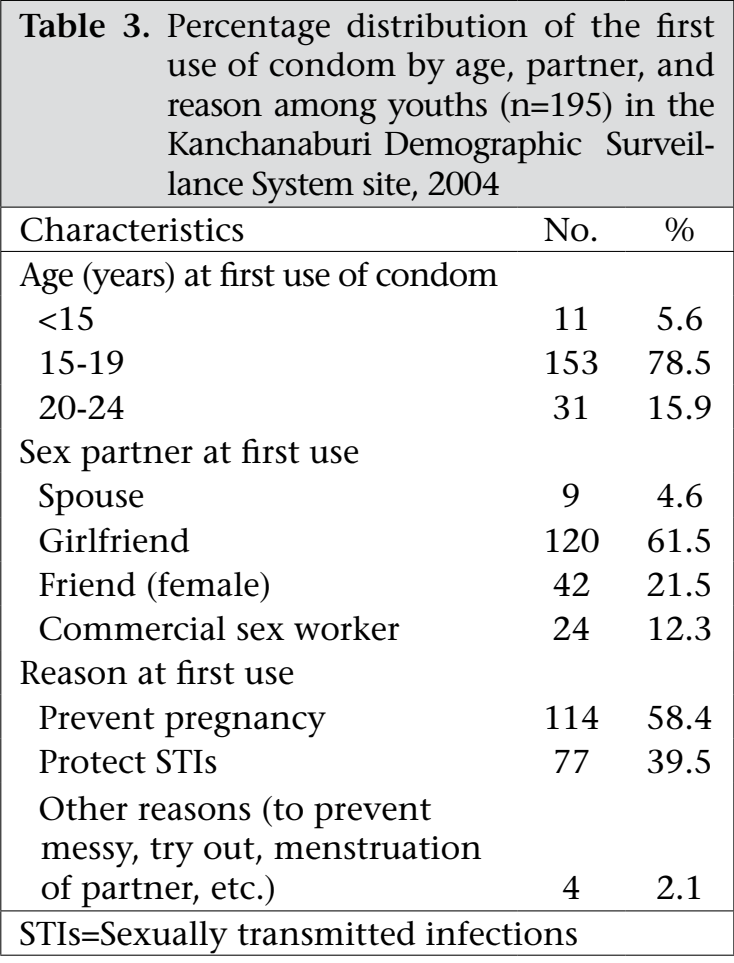

youths aged 15-19 years had used condoms for the first time. It was observed that the minimum age of the first use of condom was 12 years.

The average age at the first use of condom was 17.3 years. Further, nearly two-thirds of the first-time sexual partners were girlfriends. Of other sex partners, a small percentage comprised commercial sex workers while more than one-fifth of the first-time sexual partners were friends. More than half of the respondents used condoms to prevent pregnancy; four in 10 respondents used condoms to protect themselves from STIs/HIV, and a very small proportion, i.e. two in 10 , for other reasons.

Table 4 reveals the patterns of current use of condoms with usual or regular partners, temporary partners, and their reason for using condom. Nearly half of the youths did not use condoms regularly with their usual or regular partners. Slightly more than half used condoms with their usual partners. A large proportion was girlfriends, followed by spouses, then friends, and only a small percentage involved commercial sex workers.

The most common reason for condom-use with usual or regular partners was prevention of pregnancy, and a small percentage for prevention of STIs. However, the statistics on condom-use with temporary partners revealed that less than half of the youths were using condoms, and a large pro-

\begin{tabular}{l}
$\begin{array}{l}\text { Table 4. Percentage distribution of youths } \\
\text { (n=195) using condoms with part- } \\
\text { ners according to the last sexual epi- } \\
\text { sode and reason for using it in the } \\
\text { Kanchanaburi Demographic Surveil- } \\
\text { lance System site, 2004 }\end{array}$ \\
$\begin{array}{l}\text { Event } \\
\text { Use with regular (usual) partner }\end{array}$ \\
Yes \\
No \\
Regular (usual) partner with whom used \\
Spouse \\
Girlfriend \\
Friend (female) \\
Commercial sex worker \\
Reason of using with regular (usual) \\
partner \\
Prevent pregnancy \\
Protect from STIs \\
Other reasons \\
Use with temporary partner \\
Yes \\
No \\
Temporary partner with whom used \\
Girlfriend \\
Friend (female) \\
Commercial sex worker \\
Reason using with temporary partner \\
Prevent pregnancy \\
Protect from STIs \\
Other reasons \\
STIs=Sexually transmitted infections \\
\hline
\end{tabular}

portion was not using condoms during intercourse. It revealed that the leading temporary partners with whom youths used condoms were also girlfriends, followed by friends and commercial sex workers. The main reason for using condoms with temporary partners was protection from infections, such as STIs, followed by prevention of pregnancy.

The results in Table 5 show a strong contrast between the two groups with regard to condom-use with their partners. Single or unmarried youths were more likely to use condoms regularly with their girlfriends than with married persons. The likelihood of using condom with a friend (female) was also higher for a single person than their married counterparts. A large proportion of married youths did not use condom regularly with their partners compared to unmarried youths. The main reason for not using condom by married couples with spouse 


\begin{tabular}{|c|c|c|c|}
\hline \multirow[b]{2}{*}{ Characteristics } & \multicolumn{3}{|c|}{$\%$} \\
\hline & $\begin{array}{l}\text { Not married } \\
\text { (single) }\end{array}$ & Married & Grand total \\
\hline \multicolumn{4}{|c|}{ Condom used consistently with partners } \\
\hline Spouse & 0.0 & 2.3 & 2.3 \\
\hline Girlfriend & 32.4 & 10.4 & 42.8 \\
\hline Friend (female) & 4.1 & 1.0 & 5.1 \\
\hline Commercial sex worker & 1.1 & .0 & 1.1 \\
\hline Used sometimes with partners & 20.1 & 28.6 & 48.7 \\
\hline
\end{tabular}

was negative attitudes towards condom, such as associating condom with promiscuity.

This clearly suggests that there are substantial differences between the two groups in this study with regard to condom-use. In terms of marital status and use of condoms with different sex partners, it revealed that unmarried persons were more likely to use condoms with their partners than currentlymarried males. However, this study revealed that married males were much less likely to use condoms regularly and perceive risk of infections than nevermarried males. Nevertheless, the study emphasized the use of condoms by married women to protect them from being inadvertently infected with STIs/ HIV by their husbands. Results of the five models were prepared in the logistic regression analysis of risk perception and are summarized in Table 6 . Model 1 shows that unmarried youths were three times more likely to perceive risk and use condoms compared to married youths. Youths with different levels of education were two to nearly three times more likely to perceive self-risk and use condoms than those without schooling.

When the household wealth variable is added to Model 1, the association remained similar with the respondents from the wealthy group being nearly two times more likely to perceive risk in using condom (Model 2).

The addition of place of residence to Model 2 (resulting in Model 3) found that youths residing in urban or semi-urban areas were almost two times more likely to perceive risk.

In Model 4, created through the addition of access to television and radio to Model 3, it was found that those with access to TV were slightly more than one and half times more likely to perceive self-risk in using condom.

Model 5, generated by adding type of sexual partners (regular and temporary) and substance-use (like beer and liquor consumption) to Model 4, re- vealed that youths indulging in sex with temporary partners were almost four times more likely to perceive risk of infections while those who were habituated to drinking liquor were $26 \%$ less likely to perceive risk of STIs in relation to using condoms.

\section{DISCUSSION}

This study documented the patterns of condom-use among youths in the Kanchanaburi Demographic Surveillance System (KDSS) site and examined the extent to which characteristics of youths aged 1524 years were associated with risk perception. The difference, according to the results of analysis, was understood in terms of different characteristics. The youth population needs to take appropriate measures from conducive factors specific to individuals and protect themselves from STIs/HIV based on self-assessment of perceiving risk.

The minimum age, at first use of condom, of youngsters who had indulged in sex was 12 years, and the mean age was 17 years. The higher age at first sexual act is indicative of varying sexual practices among youths in the Kanchanaburi Demographic Surveillance System. The timing of sexual debut also affects the risk of infection with HIV and other STIs. One reason why the early onset of sexual activity is a risk factor for acquiring an STI is that the period of potential exposure to infection is longer. Furthermore, this study revealed that the large majority $(78.5 \%)$ of the respondents were engaged in sexual activity using condom before the age of 20 years. It can be said that the pattern of condom-use was more prominent among the younger people compared to the older ones within the considered age-group of youths. This may be due to the effect of many health-education programmes, peer-group programmes, youth leaders, and friend corners in Thailand (40). Nowadays, condom-promotion programmes are targeted to the young people, and the young people are more willing to experiment with sex and condom-use. The young people are curious about new experiences, including sexual 


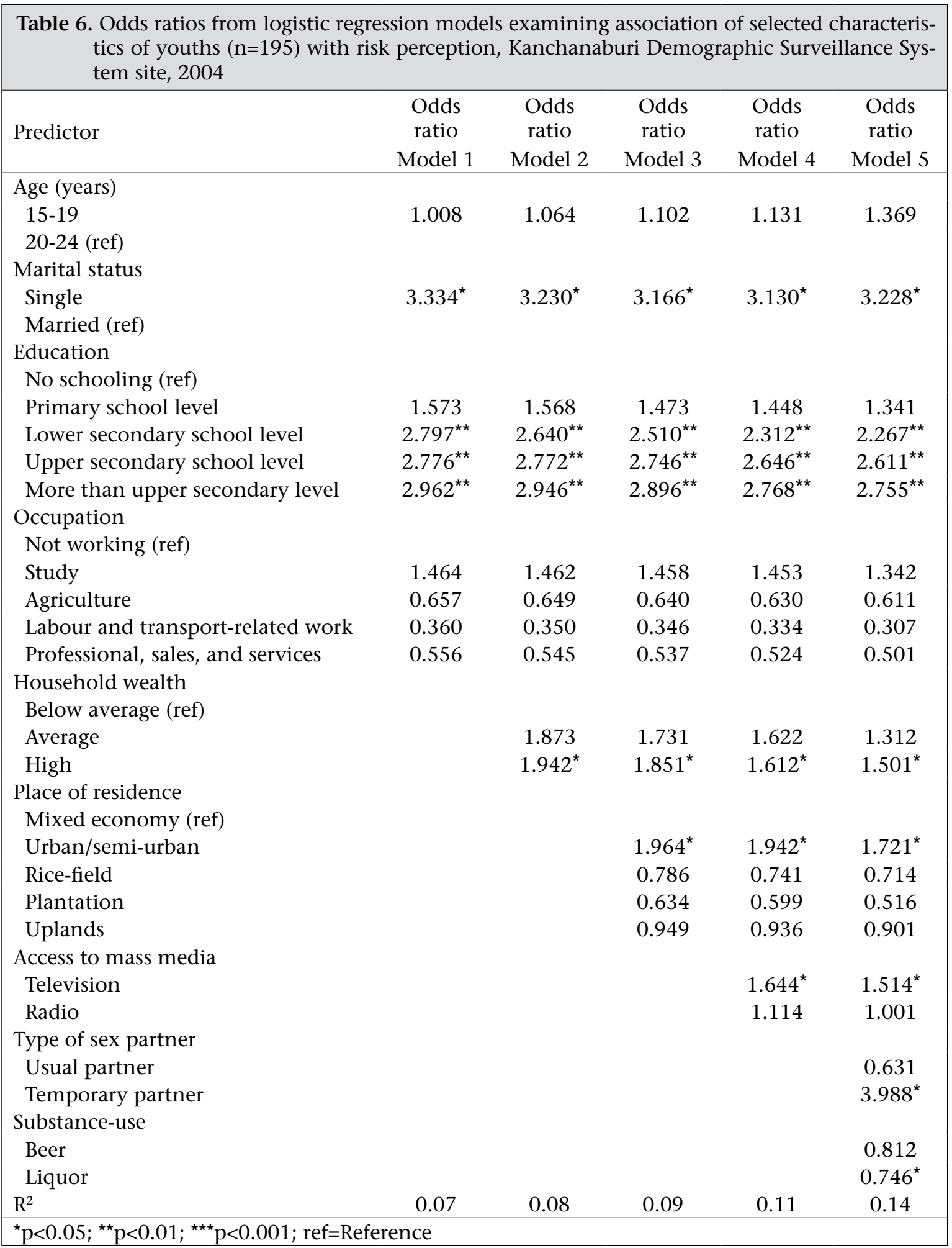

experience. At the same time, they are also likely to be more apprehensive of STIs and unwanted pregnancy (41).

According to the results of this study, the first person with whom most youths used a condom was a girlfriend or a friend (female) rather than a commercial sex worker. This outcome, which contradicts outcomes from previous studies in Thailand, suggests that condom-use was popular for commercial sex workers in the past. However, the current study has shown that condom-use has shifted to be used 
with girlfriends, which accounts for more than 60\% among the persons at first use. In the Thai cultural context, males commonly initiated their first sexual intercourse at a fairly early age by patronizing a commercial sex worker; however, nowadays, the focus has shifted to sexual networking with nonsex workers. With high awareness about the transmission of HIV through sex, an increasing number of men have most likely suspended their sexual experience with commercial sex workers and have their girlfriends as the first partner.

In addition, the study also notes that a greater proportion of unmarried youths had girlfriends and not prostitutes as their usual or regular partners. The temporary partners also comprised primarily girlfriends and friends (female), followed by commercial sex workers. The proportion of commercial sex workers as temporary partners was higher than that as regular or usual partners. The percentage of condom-use with temporary partners was lower than regular partners. Of the youths, it was found that five in 10 condom-users used condoms with usual or regular partners, and four in 10 used condoms with temporary partners respectively. The current study also discovered that the common reason for using condoms with temporary partners was to protect against infections (STIs/HIV) while, for regular partners, the primary reason for condom-use was to prevent pregnancy. The perception of using condom is different for different types of partners used by youths during sexual intercourse. These findings suggest that the youths may be aware of STIs, such as HIV/AIDS, and hence, they intended to have sexual intercourse with their friends rather than with commercial sex workers.

The supply of condoms is an important factor in determining condom-use. Supply of condoms consists of availability of and accessibility to condoms. The study found that the most common source of condoms was drug-stores. Since the $100 \%$ condom-use programme was implemented in Thailand, there have been many campaigns aimed at helping people understand how to use condom and from where condom is available, and information on the availability of condoms was circulated everywhere. However, using condom also varied for some other reasons.

In terms of marital status, it was determined that unmarried youths were more likely to perceive risk and use condoms than married youths. The study found, in both bivariate and regression analyses, that married males were much less likely to perceive risk and use condoms than never-married males. Condom-use also depended on who the sexual partners were. The reason for lack of condom-use was that they did not prefer using condom with wife and believed that it should be used only with sex workers. This result seems to corroborate the findings of a study in Thailand that the use of condoms even with spouse for contraceptive practices is low at $1.7 \%$ (42). In addition, it was expected and obvious that condom-use should be lower among married and cohabiting people because they are more likely to be monogamous and to trust each other. The study confirmed that Thai women were vulnerable to HIV infections because of unprotected sex with their husbands or partners.

The study revealed that education played an important role in risk perception which increased as the level of education increased. The level of education possibly increases response to prevention messages and encourages condom-use. Education could increase knowledge and understanding of all forms of protection and barriers. It could also enhance an individual's sense of efficacy and control, both of which could reduce the tendency to engage in risky sex. The current trend among youth users also showed that those living in urban and semiurban residences were more likely to use condom and perceive risk than those living in mixed area of residence. This may be due to the fact that access to condoms was easier for them in urban and semi-urban areas, and a high percentage of educated and non-agricultural youths in the urban areas may have enough entry to the sources of condoms compared to mixed economy area. The present study states that the respondents were more likely to receive information from television than radio. The study also revealed that consumption of liquor reduced the risk perception of STIs in relation to condom-use.

The findings of this study of young people in the Kanchanaburi DSS in Thailand suggest that the prevention of STIs/HIV and the problem of unsafe sex must be addressed together. Married persons are having both regular and temporary partners (beyond their wives). However, married persons are more reluctant to use condoms with their extramarital and marital partners and are less likely to perceive risks of STIs. Thus, they could be the bridging population with unsafe sexual behaviour, and hence, they are more likely to transmit HIV in the general population. The perception of risk is also affected by the type of partners young people indulge in sex with. Youngsters perceive more risk of STIs 
in temporary partners than with regular partners and use condoms accordingly. Demographers and other public health-oriented social scientists have long recognized the role that HIV can play in the population dynamics and the effects that changing population dynamics can have an impact on epidemiology. With the devastating demographic impact of HIV/AIDS globally, population scientists and public-policy experts are beginning to ask what kinds of effects the pandemic will have on population, including its influence on mortality and fertility. This study indicates that beliefs and behaviour concerning risk perception may strongly influence how people navigate sexual relationships in the era of HIV/AIDS.

In this study, it has already been observed that young, unmarried, educated people with high economic status were a key determinant of risk perception and condom-use. The study also identified education as one of the major predictors to increase the risk perception of infection among youths and consumption of liquor as a factor that impedes risk perception of infection in condom-use among the young population. This also suggests that the level of education increases response to perception of risk and promotion of condom and highlights the need for special efforts to reach men with educational attainment. The gap between the educated and the uneducated in risk perception is significant. As the level of education increases, some types of risky sexual behaviour decrease. Since education increases the perception of risk, the educated people can judge other major contending views viz-a-viz safe sex practice in the light of the growing epidemic. As education advances the idea that people automatically respond 'yes' when they are asked if they have changed their behaviour because they have internalized this as the most desirable way of reducing risk by using condom.

In addition, the above observations tell us that youths of lower age-group initiate condom-use rather earlier than their elderly counterparts and has girlfriends and friends (female) as regular and temporary partners, followed by commercial sex workers. Perception of risk and condom-use vary upon the type of partners chosen. The study also found that marital status, socioeconomic factors, access to media, and place of residence were the determinant predictors among youths of self-risk perception and condom-use.

Due to the social dimensions of HIV/AIDS, one has to face the new and exceptionally-difficult challenges in conducting investigations for research.
It is difficult to be certain whether premarital and extramarital sexual behaviours really are becoming more common among young people because sexual behaviour among young people has not been measured consistently over time. It was assumed that the few people who are engaged in it would not admit it anyway. In addition, future research may combine ecological variables, such as characteristics of the community and neighbourhood with family, parent-youth communications, parental attitudes towards sexuality of youths, relationship with parents, relationship with siblings, living with family, family control, and peer sexual experience, for a deeper understanding of sexual behaviour of youths.

The attitudes towards the risk involved in sexual activity differ by partner. Although youths tend to think that intimacy offers a degree of protection, friends rely more frequently on each other as a relational strategy to reduce risks. So, the fact that perception of risk is positively associated with odds of using condom is, therefore, supported, and this may help people realistically estimate their risk and take steps to address this risk in situation-specific and partner-specific scenarios. Individual decisions about protection have to be made over and over again, rather than once and for all, and they are influenced by other factors besides health considerations. The perceived risk of premarital sexual relationships, particularly for youths, depends on the notion that the relationship is of a love. Moreover, since the premarital sexual relationship is increasingly imagined as a courtship strategy that can lead to marriage, the procreative potential of a relationship becomes an important dimension of both its morality and the extent to which it is like a marriage. So, this notion can divert the young people's attitudes towards unprotected sex without perceiving risk. Repeated programme exposure is needed to achieve a behaviour change. The Government of Thailand already curved down the epidemic through $100 \%$ condom programme, in combination with other prevention efforts, and this has proved very effective at discouraging unprotected intercourse in establishment-based sex work (43). It now needs to strengthen and increase prevention efforts, especially among youths who still exhibit high-risk sexual behaviours. This study found that reported sexual union with girlfriends and other partners, by and large, indicate uneven condom-use among youths. The results of the study suggest that an individual's perceived risk of STIs/HIV infections has crucial effects on condom-use in sexual union. Perception of risk is to be considered the first stage 
towards behavioural change from risk-taking to safer behaviour. Since many young people may not see their risky sexual behaviour as problematic and, therefore, will not be ready to initiate change, it is essential to help them change their perception. Increasing 'risk perception' to promote condom-use may be at the heart of interventions. Many factors contribute to the motivation for condom-use and should be assessed individually. Youths need to make realistic risk assessments and identify positive ways of incorporating condoms into their sexual lives. Hence, future programmes can enhance their effectiveness by using a mix of mass media and interpersonal communications to repeatedly expose youths to key campaign messages.

In conclusion, the results of analysis showed that marital status, education, household wealth, living in urban and semi-urban areas, access to TV, type of partner (temporary), and liquor consumption were significant factors that affected risk perception of infections in using condoms. It is also worth noting that age and occupation showed no significant association with perceived self-risk.

\section{ACKNOWLEDGEMENTS}

The data based on which this analysis is done were collected by the Institute for Population and Social Research, Mahidol University, as part of the Kanchanaburi Demographic Surveillance System which is funded by the Welcome Trust (UK) through the Institute for Population and Social Research, Mahidol University. The authors express their sincere gratitude and thanks for the support provided by the above organizations to accomplish the task.

\section{REFERENCES}

1. World Health Organization. Treatment for sexually transmitted infections has a role in HIV prevention. Geneva: World Health Organization, 2006:1. (http:// www.who.int/mediacentre/news/releases/2006/ pr40/en/index.html, accessed on 2 October 2007).

2. United Nations Children's Fund. Young people and HIV/AIDS-opportunity in crisis. New York, NY: United Nations Children's Fund, 2002. 35 p.

3. United Nations AIDS. Epidemic update, Fact Sheet Asia, last updated December 2006:6. (www.unaids. org, accessed on 21 January 2008).

4. Prasartkul P, Chamratrithirong A, Bennett A, Chitwatanapact L, Isarabhakdi P. Rural adolescent sexuality and the determinants of provincial urban premarital adolescent sex. Bangkok: Institution for Population and Social Research, Mahidol University, 1987. 113 p.

5. Chai P, Xenos P, Varangrat A. The risk of premarital sex among Thai youth: individual and family influences. J Pop Soc Stud 2001;12:1-31.
6. Punpanich W, Ungchusak K, Detels R. Thailands' response to the HIV epidemic: yesterday, today and tomorrow. AIDS Educ Prev 2004;16:119-36.

7. van Griensven F, Thanprasertsuk S, Jommaroeng R, Mansergh G, Naorat S, Jenkins RA et al. (Bangkok MSM Study Group). Evidence of a previously undocumented epidemic of HIV infection among men who have sex with men in Bangkok, Thailand. AIDS 2005;19:521-6.

8. Pliplat T, Kladsawas K, van Griensven F, Wimonsate W. Results of the HIV surveillance among men who have sex with men (MSM) in Bangkok, Chiangmai and Phuket. In: Proceedings of the Department of Disease Control Annual Conference. Bangkok: Department of Disease Control, Ministry of Public Health, Royal Government of Thailand, 2008:12-5.

9. Choopanya K, Tappero JW. Preliminary results of a phase III HIV vaccine efficacy trial among injecting drug users in Thailand (abstract). In: Abstracts of Fifteenth International Conference on AIDS, Bangkok, 11-16 July 2004:1427.

10. Langkafah F, Otani A. Peer education: available methodology for HIV and AIDS prevention among Thai youth in northern Thailand (abstract). In: Abstracts of Seventh International Congress on AIDS in Asia and the Pacific, Kobe, 1-5 July 2005:22.

11. Jeanine B, Robert B, Laxmi B A, Txema C, Cheng H, Cheng $\mathrm{F}$ et al. Monitoring the AIDS pandemic report. AIDS in Asia: face the facts; a comprehensive analysis of the AIDS epidemics in Asia. MAP report, 2004. 23 p.(http://www.mapnetwork.org/reports/aids_in_asia. $\mathrm{html}$, accessed on 12 January 2008).

12. Sweat M, Nopkesorn T, Mastro TD, Sangkharomya S, Pokapanichwong W, MacQueen K et al. AIDS awareness among a cohort of young Thai men: exposure to information, level of knowledge, and perception of risk. AIDS Care 1995;5:573-591.

13. Thato S, Charron-Prochownik D, Dorn LD, Albrecht SA, Stone CA. Predictors of condom use among adolescent Thai vocational students. J Nursing Scholarship 2003;35:157-63.

14. Ahmed S, Lutalo T and Wawer M. HIV incidence and sexually transmitted diseases prevalence associated with condom use: a population study in Rakai, Uganda. AIDS 2001;15:2171-9.

15. Im-Em W. Partner relations and AIDS in Chiang Mai villages. Canberra: Australian National University, 1996:25-55.

16. Blum RW, McNeely C, Nonnemaker J. Vulnerability, risk and protection. J Adolescent Health 2002;31:2839.

17. Short JF, Jr. The social fabric of risk: towards the social transformation of risk analysis. Am Soc Rev 1984;49:711-25. 
18. Smith DJ. Imagining HIV/AIDS: morality and perceptions of personal risk in Nigeria. Med Anthropol 2003;22:343-72.

19. Rayner S, Cantor R. How fair is safe enough? The cultural approach to societal technology choice. Risk Analysis 1987;7:3-9.

20. Weinstein ND. Unrealistic optimism about future life events. J Personal Soc Psychol 1980;39:806-20.

21. Scherer CW, Cho H. A social network contagion theory of risk perception. Risk Analysis 2003;23:261-7.

22. Prata N, Morris L, Mazive E, Vahidnia F, Stehr M. Relationship between HIV risk perception and condom use: evidence from a population-based survey in Mozambique. Int Fam Plann Perspect 2006;32:192-200.

23. Cleland J. Risk perception and behavioral change. In: Cleland J, Ferry B, editors. Sexual behavior and AIDS in the developing world. London: Taylor and Francis, 1995;157-92.

24. Akwara PA, Madise NJ, Hinde A. Perception of risk of HIV/AIDS and sexual behavior in Kenya. J Biosoc Sci 2003;35:385-411.

25. Ngamprapasom N. The first sexual intercourse of Thai men. Bangkok: Institute for Population and Social Research, Mahidol University, 2000:25-35.

26. Jenkins RA, Torugsa K, Mason CJ, Jamroenratana V, Lalang C, Nitayaphan S et al. HIV risk behavior patterns among young Thai men. AIDS Behav 1999;3:335-46.

27. O'Connor ML. A major HIV risk factor facing many Thai women is the sexual behavior of their husband or partner. Int Fam Plann Perspect 1998;24:198-9.

28. Knodel J, Pramuralratana A. Prospects for increased condom use within marriage in Thailand. Int Fam Plann Perspect 1996;22:97-102.

29. Caraat M. The relationship between sexual behaviour and level of education in developing countries. UNAIDS-best practice digest 2000:3. (http://nzdl.sadl. uleth.ca/cgi-bin/library?, accessed on 25 March 2008).

30. Oddens BJ, Lehert P. Determinants of contraceptive use among women of reproductive age in Great Britain and Germany. I: Demographic factors. J Biosoc Sci 1997;29:415-35.

31. Guaykietikul P, Thongchaoen N, Voratis L. Health education on condom use in male attendants of Samutprakan STD clinic. J Health Sci 1994;3:104-13.

32. Institute for Population and Social Research. Report of $4^{\text {th }}$ round survey (2003): Kanchanaburi Demography Surveillance System Project. Bangkok: Institute for Population and Social Research, Mahidol University, 2004:12-55.
33. Institute for Population and Social Research. National sexual behavior survey, Thailand. Bangkok: Institute for Population and Social Research, Mahidol University, 2006:338. (http://www.ipsr.mahidol.ac.th, accessed 21 July 2008).

34. VanLandingham M, Suprasert S, Sittitrai W, Vaddhanaphuti C, Grandjean N. Sexual activity among never-married men in northern Thailand. Demography 1993;30:297-313.

35. Liu A, Kilmarx P, Jenkins RA, Manopaiboon C, Mock $\mathrm{PA}$, Jeeyapunt $\mathrm{S}$ et al. Sexual initiation, substance use, and sexual behavior and knowledge among vocational students in northern Thailand. Int Fam Plann Perspect 2006;32:126-35.

36. Rogers RG, Hackenberg R. Extending epidemiologic transition theory: a new stage. Soc Biol 1987;34:23443.

37. Hiltabiddle SJ. Adolescent condom use, the health belief model, and the prevention of sexually transmitted disease. J Obstet Gynecol Neonat Nurs 1996;25:616.

38. Institute for Population and Social Research. Report of baseline survey, 2000. Kanchanaburi Demography Surveillance System (KDSS) Project. Bangkok: Institute for Population and Social Research, Mahidol University, 2001:11-39.

39. Institute for Population and Social Research. Report of $5^{\text {th }}$ round survey, 2004. Kanchanaburi Demography Surveillance System (KDSS) Project. Bangkok: Institute for Population and Social Research, Mahidol University, 2005:22-45.

40. Fongkaew W, Fongkaew K, Muecke M. HIV/sexual and reproductive health program for HIV prevention: the youth-adult partnership with school approach. $J$ Med Assoc Thailand 2006;89:1721-32.

41. Murphy JJ, Boggess S. Increased condom use among teenage male, 1988-1995: the role of attitudes. Fam Plann Perspect 1998;30:276-303.

42. Thailand. Ministry of Public Health. Thailand reproductive health profile by Reproductive Health Division. Bangkok: Department of Health, Ministry of Public Health, Royal Government of Thailand, 2003:32-55

43. Chamratrithirong A, Thongthai V, Boonchalaksi W, Guest P, Kanchanachitra C, Varangrat A. The success of the $100 \%$ condom promotion programme in Thailand: survey result of the evaluation of the $100 \%$ condom promotion programme in Thailand. Bangkok: Institute for Population and Social Research, Mahidol University, 1999. 124 p. 